\title{
Editorial
}

\section{THE FUTURE OF PSYGHOPATHOLOGY}

$\mathrm{P}$ SYCHOPATHOLOGY, using the term in the sense of a psychological approach to the problems of the causation and mode of production of disease, is a subject of comparatively recent growth. Indeed, although its roots lie farther back, it cannot be said to have established any claim to incorporation in the field of science before the work of the French psychologists at the end of last century, notably the researches of Pierre Janet. Since that time, however, its growth has been rapid, and it has now become a wide-spreading tree with many branches. This later development has been dominated by the methods and theories of Freud, which have indubitably influenced to a greater or less extent all other workers in this field, although only a comparatively small number accept his views and principles in their entirety.

It cannot be denied that the work of the psychopathologists has enabled us to acquire a better understanding and control of certain disorders, notably the psychoneuroses. Nevertheless, there are features in the position of psychopathology to-day which arouse some disquietude and even bewilderment. It includes within its borders a number of schools of thought, divergent from one another not merely in details of method but in fundamental principles, each confidently putting forward conceptions in explanation of the same phenomena which are radically irreconcilable with one another. This divergence and irreconcilability no doubt are less profound than they appear at first sight to be, and many common features can be discerned when the matter is closely investigated, but the differences are clearly greater than can be found within the borders of any other subject claiming to follow the method of science.

It can easily be understood, therefore, that certain critics have turned from an enthusiastic contemplation of the spread and luxuriant foliage of the tree to an examination of the roots and soil upon which it is based, and have questioned whether these are solid and capable of supporting the structure which has grown from them. Such criticism can be directed to two fundamental points, which must be carefully distinguished from one another. In the first place it may be questioned whether 
it is even possible to construct scientifically valid psychopathological conceptions, that is to say, whether the fundamental postulate of psychopathology - that behaviour and the sequence of conscious processes can be adequately resumed in formulæ couched in psychological terms and yet fashioned according to the rules of scientific method-is valid or false. In the second place, it may be asked whether, if such conceptions are possible, the conceptions which psychopathology actually puts forward have in fact been constructed by the use of scientific method, that is, by the observation of phenomena and the formation of formulæ resuming these phenomena and verifiable by the testing of further phenomena.

Dr. E. Mapother, in a witty and entertaining presidential address to the Section of Psychiatry of the Royal Society of Medicine, answers both these questions with an emphatic negative. He makes a vigorous onslaught upon the whole structure of psychopathology, and affirms not only that its methods are unsound, but that its basic principles are false and essentially incompatible with scientific method. He holds that the determining quality of conscious purpose, which is clearly a fundamental postulate in the psychologies of Freud and the other schools which have diverged from him, is completely illusory, that behaviour cannot be explained by conceptions constructed in psychological terms, that consciousness is nothing but awareness of happenings in our own body, and hence that formulæ by which science may hope to resume sequences of conscious phenomena can only be established in terms of those happenings. For him the 'psychological determinism' of Freud is not the determinism of scientific method, and he regards the concepts of psychopathology as necessarily linked with the acceptance of animism and free-will.

All these are highly debatable propositions, largely dependent upon philosophical preconceptions, and in his endeavour to eradicate what he evidently feels to be a canker at the heart of psychiatry Dr. Mapother has used a bludgeon in a field where a rapier would be more effective. After all, science is only a special application of the inductive method, its particularity consisting in the requirement that the inductions must be verifiable, and capable of leading to the prediction and control of future phenomena. It is questionable whether the attempt to impose further limitations on this definition, and to insist that the application of scientific method to new fields should always conform to limitations which have proved successful in very different fields, will not hinder progress. One 
is reminded of Planck's distinction between purist and pragmatic scientists. The former 'strive always after a perfect co-ordination of the accepted axioms of their science,' while the latter 'try to amplify the accepted first principles by the introduction of new ideas and thus send out feelers in all directions for the purpose of making progress.' It is surely possible that such amplification may take the form of endeavouring to construct formulæ in psychological terms to resume the sequence of phenomena constituting human behaviour while holding fast to the requirement that the process shall be governed by the rules of scientific method.

Dr. Mapother is on surer ground in his criticism of the actual achievements of psychopathology, and when he is contending not that they intrinsically cannot, but that they in fact do not, satisfy the requirements of scientific method. He recapitulates the objections of former critics to Freud's psychoanalytic procedure, the privacy of the observations, so that the phenomena cannot be publicly verified, and the possibility of distortion owing to the peculiar circumstances of the investigation. These objections seem to be valid, and to reduce Freud's method to a level definitely below that required by science. Privacy of observation is probably inevitable in the recording of certain ranges of behaviour, but verifiability, and elimination or estimation of the personal equation, are essential factors in scientific method. Unless, however, we are to adopt the position that such ranges of behaviour are forever incapable of scientific investigation, we may hope that by further refinement the distorting factors will be capable of recognition and assessment, and in the meantime only accept generalizations built upon observation of this kind with the utmost caution, and a full understanding of the possibilities of error.

Dr. Mapother further puts forward caustic but salutary criticism of the tendency of some psychopathologists to construct concepts which are nothing but invented entities whose sole function is to produce the phenomena they are invoked to explain. The arbitrary postulation of 'instincts' and their reification as 'causes' responsible for behaviour is an example in point. Certain psychopathologists have undoubtedly merited castigation in this respect, but it is probably not legitimately applicable to the concepts which Freud uses, however vulnerable these may be on other grounds. It is unlikely that any competent psychoanalyst would deny that such concepts as ' complex,' 'id' and ' ego' are merely convenient symbols for formulating the routine of experience, and 
that they are not to be regarded as subsisting spiritual entities whose activities are conditioned by free-will. The constant and careful recognition of this point, however, upon which Dr. Mapother insists, will no doubt tend to curtail the extravagant weaving of flimsy abstractions to which psychopathologists are sometimes addicted.

Lastly, Dr. Mapother urges that there must be continuity between neurology and psychiatry, and that endeavour should be concentrated upon extending to higher levels of human activity the concepts which are in contact with the whole biological field, and which neurology has found to be fruitful in understanding lower levels of activity. There can be no question that this aim is laudable and that it should be persistently pursued, but this does not mean that attempts must not be made to formulate the experiences of these higher levels by the aid of conceptions which may be more easily applicable to their peculiar nature. In the present state of our knowledge formulæ couched in psychological terms can resume sequences of behaviour and speech which are as yet inaccessible to any profitable neurological approach, and surely therefore such formulæ can be legitimately constructed. Naturally this does not imply that the march of neurological knowledge may not ultimately embrace these processes in formulæ applicable to the whole biological field, and therefore more general and fundamental. Nor does the use of psychological conceptions involve postulating the entire independence of a mental series of phenomena from all others, but only that certain ranges of human activity are at present formulated most profitably in psychological terms.

It is certainly desirable that psychopathology, when it devises concepts to resume the phenomena which it oberves in its special sphere, should have due regard to the concepts which neurology has formulated to resume analogous phenomena at lower levels of activity, and endeavour to advance along a line consonant with a wider biological application. Dr. Emanuel Miller, in his presidential address to the Medical Section of the British Psychological Society, has emphasized this principle, and pointed out that it may be feasible to winnow the vocabulary of psychopathology and to do away with many terms which have already their analogues in biology and neurology, the latter being better terms because they are applicable over a wider field.

The multiplicity and diversity of schools in which psychopathology, like psychology itself, has an unenviable pre- 
eminence, and the dispute of opinion regarding its methods and fundamental principles, make it difficult to forecast its future. It is conceivable that the failure of many of its later developments adequately to satisfy the demands of scientific method, and a more rigid insistence upon the verifiability which is the corner-stone of that method, may lead to. a pruning of overambitious flights, a return to the level of Janet's epoch-making researches, with the methods of which no scientist can quarrel, and a renewed attempt to build a higher structure thereon. It is probable, however, that the future of psychopathology will be determined, as always in the history of science, by its workers and their achievements rather than by its critics. 